Geograficando, vol. 17, n 1, e095, mayo - octubre 2021. ISSN 2346-898X

Universidad Nacional de La Plata.

Facultad de Humanidades y Ciencias de la Educación.

Departamento de Geografía

\title{
La Cuestión Malvinas ante la crisis y transición del sistema mundial: perspectivas frente al Brexit
}

\author{
The Malvinas Question in the face of the crisis and transition of the world \\ system: prospects on Brexit
}

Julián Bilmes

bilmesjulian@gmail.com

Centro de Investigaciones Socio-Históricas. Instituto de Investigaciones en Humanidades y Ciencias Sociales. Facultad de Humanidades y Ciencias de la Educación. Universidad Nacional de La Plata. CONICET, Argentina

Recepción: 13 Noviembre 2020

Aprobación: 08 Febrero 2021

Publicación: 03 Mayo 2021

Cita sugerida: Bilmes, J.(2021). La Cuestión Malvinas ante la crisis y transición del sistema mundial: perspectivas frente al Brexit. Geograficando, 17(1), e095. https://doi.org/10.24215/2346898Xe095
Resumen: La Cuestión Malvinas enfrenta un escenario geopolítico por demás dinámico y convulsionado, ante la crisis y transición del sistema mundial en creciente profundización, desde la fase Brexit-Trump después de 2016 y la nueva fase que se abre en la actualidad, a raíz de la pandemia de COVID-19. Se aborda en este trabajo cómo se sitúa el sistema Malvinas, Atlántico Sur y Antártida en este marco, y en particular frente a la salida británica de la Unión Europea (UE). Desde una perspectiva geopolítica, y valiéndose de un enfoque sistémico mundial, se analizan las fuerzas en disputa y los posibles escenarios futuros para la Cuestión Malvinas. Se concluye que el Brexit puede implicar tanto una amenaza como una oportunidad para el histórico reclamo argentino de soberanía sobre las islas del Atlántico Sur y espacios marítimos circundantes, según cómo se lo afronte desde el lado argentino.

Palabras clave: Caos sistémico mundial, Sistema Malvinas, Atlántico Sur y Antártida, Salida británica de la Unión Europea, Gran Bretaña Global, Soberanía integral.

Abstract: The Malvinas Question faces an extremely dynamic and convulsed geopolitical scenario, in the face of the crisis and transition of the world system that increasing deepen, from the Brexit-Trump phase after 2016, and the new phase currently underway due to COVID-19. This paper deals with how the Malvinas, South Atlantic and Antarctic system is situated in this framework, and in relation to the British exit from the European Union (EU). From a geopolitical perspective, and using a global systemic approach, the forces in dispute and possible future scenarios for the Malvinas Question are analyzed. It is concluded that Brexit can imply both a threat and an opportunity for Argentina's historic claim to sovereignty over the islands of the South Atlantic and surrounding maritime spaces, depending on how it is dealt with on the Argentine side.

Keywords: Global systemic chaos, Malvinas, South Atlantic and Antarctica system, British exit from the European Union, Global Britain, Integral sovereignty. 
“(...) de prodigiosa importancia podría resultar una base conveniente, situada tan al sur, y tan cerca del Cabo de Hornos (...) Esto, incluso en tiempos de paz, podria ser de gran consecuencia para esta Nación, y en tiempos de guerra, nos haría dueños de esos mares." George Anson, comodoro de la Marina Real británica (nombrado luego Primer Lord del Almirantazgo), en su libro de 1748 Un viaje alrededor del mundo (Brown, 1987)

"El Reino Unido es una potencia global con intereses verdaderamente globales. Una nación con la quinta economía más grande del planeta (...) con el quinto mayor presupuesto de defensa del mundo y el segundo mayor exportador en materia de defensa. $Y$ dado que el nuevo Gran Juego Global se jugará en un campo de juego global, debemos estar preparados para competir por nuestros intereses y nuestros valores lejos, lejos de casa (...) Brexit nos ha traido a un gran momento en nuestra historia. Un momento en el que debemos fortalecer nuestra presencia global, aumentar nuestra letalidad y aumentar nuestra masa."

Gavin Williamson, Secretario de Defensa británico en el período 2017-2019, en su discurso en la usina de pensamiento sobre defensa y seguridad internacional RUSI (Royal United Services Institute) (Williamson, 2019)

\section{INTRODUCCIÓN}

La actual situación mundial se presenta altamente convulsionada y dinámica. Este siglo en curso ha dado luz a grandes cambios en el ordenamiento mundial, los cuales han horadado muy profundamente las bases de sustentación tanto del régimen de acumulación neoliberal, con comando del capital financiero y las transnacionales occidentales, como de la hegemonía estadounidense, angloamericana y occidental. La emergencia y creciente relevancia de polos de poder alternativos, principalmente en Asia-Pacífico, nuevo polo dinámico de acumulación a nivel mundial, ha dado lugar a importantes reconfiguraciones del mundo desde fines de siglo pasado y principios del actual. La crisis en curso desatada por la pandemia de COVID-19 no ha hecho más que profundizar estas tendencias, actuando como una suerte de catalizador de ellas (Ramonet, 2020; Bilmes, Dubin y Liaudat, 2020).

Diversas nociones se han propuesto para caracterizar este proceso: "caos sistémico", "transición históricoespacial", "transición geopolítica" o "transición hegemónica" son algunas de ellas (Grosfoguel, 2016; Gandarilla, Jalife-Rahme, Ceceña, Borón y Bruckmann, 2016; Merino y Narodowski, 2019, entre otros), en las que se remarca la situación de crisis y transición del sistema mundial constituido por las potencias occidentales pos Revolución Industrial de los siglos XVIII y XIX, bajo hegemonía británica, y pos Bretton Woods, luego de la Segunda Guerra Mundial, bajo hegemonía estadounidense. Someramente, podemos destacar un conjunto de dimensiones de este proceso: a) tendencia al desplazamiento del "centro de gravedad" de la economía y el poder mundial de Oeste (u "Occidente") a Este (u "Oriente"), esto es, del Atlántico Norte a la zona Asia-Pacífico (las raíces de este desplazamiento se remontan a los años setenta del siglo pasado, y se han acentuado en este siglo XXI); b) declive de la hegemonía angloamericana occidental y emergencia de una creciente multipolaridad relativa, con alianzas internacionales (siendo China-Rusia la principal) que tienden a desplazar a Estados Unidos (EE.UU.) como líder y a Occidente como centro del mundo; c) crisis de la economía-mundo capitalista, luego del estallido financiero de 2007-2008, en tanto crisis de sobreacumulación y realización resuelta con financiarización y creación de burbujas especulativas (hoy día, a raíz de la pandemia se asiste a una nueva gran crisis económica, con una gran recesión y a las puertas de una crisis de deuda a nivel global); d) crisis civilizatoria, que se expresa en un conjunto de aspectos como las enormes y crecientes disparidades mundiales de riqueza y poder, procesos crecientes de precarización, pauperización y exclusión de amplias masas de trabajadores, la crisis migratoria y de refugiados, la crisis ecológica y ambiental, la sucesión creciente de brotes de epidemias, etc.; e) proliferación de resistencias y proyectos alternativos, tanto en el Sur como en el mismo Norte global, habiendo sido América Latina uno de los baluartes de este proceso en la primera década y media de este siglo.

Si bien se puede periodizar el desenvolvimiento de esta transición geopolítica mundial desde fines de siglo pasado, nos interesa destacar la fase que se abre hacia 2016, a raíz de las victorias electorales 
del Brexit (acrónimo que refiere a la salida del Reino Unido de la Unión Europea) y de Donald Trump en EE.UU., en junio y noviembre de tal año, respectivamente. Si en los años ochenta la "contrarrevolución neoconservadora" comandada por la alianza Thatcher-Reagan había sido decisiva para restaurar la primacía capitalista occidental en un mundo en crisis, impulsando el programa neoliberal y el régimen de acumulación flexible bajo comando del capital transnacional, la dupla Brexit-Trump pareció apuntar a lograr lo mismo, pero con contenido inverso. Acontecidos también en el seno del polo de poder angloamericano, estos fenómenos expresaban fuerzas y articulaciones político-sociales de signo antiglobalista y nacionalista conservador (también denominados como "populismos de derecha" por ciertos sectores intelectuales -Muñoz Portillo, 2019-) que propugnaban recuperar el antiguo esplendor imperial de sus naciones, debilitadas - paradójicamente- por el avance globalizador. Y es que las clásicas "soluciones espaciotemporales" de la sobreacumulación de capital (Harvey, 2014) habían golpeado fuertemente sobre diversas regiones anteriormente centrales y ahora periferializadas en las cadenas globales de valor (el ejemplo célebre es el "cinturón del óxido" en EE.UU.), lo que dio lugar a la desindustrialización y la pérdida de nivel de vida en amplias capas de trabajadores. De este modo, la globalización era puesta muy fuertemente en cuestión desde el seno de las mismas potencias que la habían impulsado.

En todo este marco, se ha agudizado la disputa por la hegemonía y la reconfiguración del orden mundial. Las islas y espacios marítimos del Atlántico Sur Occidental y la Antártida no son ajenas a este proceso, dada su gran relevancia geoestratégica, por lo cual la Cuestión Malvinas presenta extraordinaria vigencia e importancia para la Argentina y América Latina (entendiendo que incluye también la cuestión del Atlántico Sur y la Antártida, como complejo sistémico o "todo geopolítico" -Caplan y Eissa, 2015). De este modo, la Cuestión Malvinas constituye una "mirilla" para observar las relaciones mundiales de poder en las que se inscriben la Argentina y Sur/Latinoamérica, como también un "rostro visible" de la dependencia, al expresar en forma explícita y desnuda tanto la pervivencia del colonialismo en pleno siglo XXI como la vigencia de las disputas geoestratégicas que atraviesan al país y la región en el escenario global (Dupuy, 2018; Cisilino, 2020).

Si bien se podía observar con el correr de este siglo que el conflicto por Malvinas no implicaba sólo a Reino Unido y la Argentina, sino también a la Unión Europea (UE) y la Organización del Tratado del Atlántico Norte (OTAN) frente a los organismos de integración regional autónoma sur/latinoamericanos como la Unión de Naciones Suramericanas (UNASUR) o la Comunidad de Estados Latinoamericanos y Caribeños (CELAC), ello se complejiza en la actualidad. El caos sistémico en curso ha gestado tanto la salida británica de la UE, una latente o potencial crisis de la OTAN a raíz de la política exterior de Trump y la paralización o desmembramiento de organismos como UNASUR y CELAC a raíz del giro conservador neoliberal en la región suramericana. Así, la revitalización del reclamo soberano sobre Malvinas y las islas del Atlántico Sur por parte del gobierno argentino del Frente de Todos enfrenta un escenario geopolítico por demás dinámico y convulsionado.

En los últimos días de 2020, británicos y europeos llegaron finalmente a un Acuerdo de Salida de los primeros del bloque europeo, luego de años de negociaciones entre ambas partes, así como de una crisis política y empate hegemónico desatados en Reino Unido a raíz del referéndum del Brexit. En tal acuerdo no fueron incluidos los denominados Territorios Británicos de Ultramar, lo cual abre lugar a fuertes impactos sobre sus economías. Nos centraremos aquí en lo que concierne a Malvinas, las islas y espacios marítimos del Atlántico Sur, la más antigua controversia de soberanía del sistema internacional y la más sentida causa nacional en la Argentina y Suramérica. Según se sostiene en este trabajo, si bien aparece la posibilidad de fuertes impactos del Brexit sobre la economía isleña y sobre el mismo Reino Unido, además de ponerse en cuestión la relación de este último con la Unión Europea, el nacionalismo conservador británico que conduce el Brexit apuesta por redefinir su rol mundial - "Gran Bretaña Global” es su lema- y resulta central para ello afianzar sus relaciones con sus históricas áreas de influencia, como sus territorios de ultramar y la Commonwealth. 
En este marco, son enormes los desafíos del nuevo gobierno argentino para recuperar autonomía y márgenes de maniobra geoestratégicos, revertir la política desmalvinizadora y la cesión de soberanía del gobierno anterior (concebidas en pos de "reinsertarse en el mundo" -occidental-), aprovechar las oportunidades que brinda la transición histórica en curso y hacer frente a las pretensiones británicas de afianzar su proyección de poder sobre Malvinas, Atlántico Sur y Antártida.

Este trabajo aborda, pues, cómo se sitúa la Cuestión Malvinas en esta crisis y transición del sistema mundial, en términos generales, y en particular frente al Brexit. Desde una perspectiva geopolítica, con perspectiva situada desde el Sur global, y valiéndose de un enfoque sistémico mundial, se analizan las fuerzas en disputa y los posibles escenarios futuros para la Cuestión Malvinas. Se ha trabajado con bibliografía especializada sobre el tema como también con un conjunto de fuentes primarias y secundarias: informes y documentos gubernamentales del Reino Unido, Malvinas y la Commonwealth, indicadores socioeconómicos, artículos periodísticos y de portales especializados. Se concluye que el Brexit puede implicar tanto una oportunidad como una amenaza para el histórico reclamo argentino de soberanía sobre las islas del Atlántico Sur y espacios marítimos circundantes, según cómo se lo afronte desde el lado argentino.

\section{Malvinas, Atlántico Sur y Antártida en la geopolítica del Siglo XXI}

Las islas Malvinas, Georgias del Sur, Sandwich del Sur y los espacios marítimos circundantes del Atlántico Sur occidental, vestigios coloniales en pleno siglo XXI del viejo imperio británico de ultramar, constituyen un enclave estratégico, con implicancias geopolíticas, económicas y militares de peso (Pérez y Barassi, 2018; Wainer, 2020). Este carácter está dado, en primer lugar, por la ubicación de las Malvinas frente al estrecho de Magallanes y próximas al pasaje de Drake y canal de Beagle, lo que da lugar al control de pasos bioceánicos Atlántico-Pacífico por el sur. El control de las islas permite el dominio del tráfico marítimo desde el sur de África y sur de América del Sur hacia el Atlántico Norte, como también la comunicación del océano Índico con el Atlántico Sur y el Pacífico Sur, vía de navegación comercial de cada vez mayor peso.

Ya desde las "Navegation Acts", en el siglo XVII, bajo el gobierno de Cromwell, y hasta la actualidad, Inglaterra comprendió que su predominio mundial se debía basar en el control de las rutas de aprovisionamiento, y que ello requería del control de los mares y de sus enclaves estratégicos (Lualdi, 2019). Mahan, uno de los exponentes de la geopolítica estadounidense, atribuía a fines del siglo XIX la condición hegemónica británica a su poderío naval, constituido por su gran marina de guerra y su comercio marítimo, sumado a sus colonias (López, 2012). Las islas Ascensión, Santa Elena, Diego García, Tristán da Cunha, Malvinas, entre otras, son ejemplos de esa estrategia de dominación. Como se puede leer en el primer epígrafe de este trabajo, del comodoro Anson, a mediados del siglo XVIII los británicos vislumbraron la importancia geoestratégica que podría tener Malvinas para sus pretensiones hegemónicas, y finalmente las usurparon en 1833.

En la actualidad, la construcción de enormes barcos graneleros y petroleros ocasiona un grave problema para atravesar el canal de Panamá, por lo que esta llave de tránsito interoceánica desde el Atlántico y el Índico hacia el Pacífico puede acrecentar nuevamente su importancia. ${ }^{1}$ Recordemos que en Asia-Pacífico (o IndoPacífico, al decir de los documentos oficiales británicos) se sitúa el nuevo polo dinámico de acumulación en este siglo en ciernes. La gran relevancia de este punto se debe a que, según estimaciones previas a la pandemia, alrededor del $90 \%$ del comercio mundial se realiza por vía marítima. A su vez, una parte importante de la denominada Ruta de la Seda marítima, parte del proyecto chino de interconexión comercial euroasiática y con proyección global, pasa por esa llave, y ante una escalada en la disputa actual entre EE.UU. y China, ese comercio podría ser obstaculizado en la zona de Malvinas.

Por otro lado, desde el "Informe Shackleton" de 1976, el Reino Unido tomó conciencia de las grandes riquezas económicas que alberga toda la zona de las islas del Atlántico Sur. La principal riqueza en la actualidad es la pesca, cuyos recursos son de importancia mundial y de gran diversidad: calamar, merluza, 
krill, algas, moluscos, cetáceos, abadejo, bacalao, entre otros. Esta actividad tuvo un auge en los años noventa a través de capitales españoles y alemanes, producto del agotamiento de los caladeros del Mar del Norte y las costas africanas. Ya en el siglo en curso cobraron protagonismo actores asiáticos: taiwaneses, surcoreanos y chinos. En la actualidad, estas flotas pesqueras son responsables de la depredación ictícola del Atlántico Sur (Ortega, Saavedra y Esquiroz, 2019). Constituye esta actividad la principal fuente de ingresos de las islas pues representa alrededor del $60 \%$ del PIB isleño. Por ello se ha caracterizado a Malvinas como un "paraíso pesquero", con base en su sistema de licencias y como parte de la red de "paraísos fiscales" de raíz inglesa (Dupuy, 2019).

La zona cuenta también con un importante potencial de recursos hidrocarburíferos offshore, es decir, en las aguas adyacentes a las islas. Ello adquirió gran relevancia luego de la primera crisis del petróleo, en 1973, lo cual motivó que el gobierno británico encargara estudios sobre el potencial de la zona. Existen, igualmente, dificultades logísticas para explotar esos hidrocarburos sin acuerdo y cooperación con la Argentina, tal como lo previera E. Shackleton. Se trata de operaciones que requieren inversiones de gran monto y alto riesgo, que demandan buenas condiciones impositivas y "seguridad jurídica". Por ello, recién a mediados de los 90 el Reino Unido lanzó una licitación pública para la exploración de petróleo en las islas; avanzó en las perforaciones a fines de esa década y cobró un importante impulso hacia 2010, con una importante campaña de exploración y prospección hidrocarburífera en toda esa zona (Bernal, 2011). En 2015 el Reino Unido anunciaba el hallazgo de petróleo en la Cuenca Norte de Malvinas y otorgaba permisos de explotación. Al año siguiente, la empresa Rockhopper anunció el descubrimiento de un yacimiento de "clase mundial" en esa cuenca. A su vez, otros recursos naturales (RR.NN.) muy importantes constituyen los nódulos polimetálicos, dado que en el lecho marino existen recursos metalíferos de manganeso, cobalto, cobre, hierro, níquel, silicio ferroso, cromo y otros metales, algunos de los cuales son considerados estratégicos y pueden adquirir relevancia en el futuro.

Cabe señalar aquí dos cuestiones importantes sobre esta disputa global por el acceso a, y disponibilidad sobre, los RR.NN. (o bienes comunes). Según señalan diversos autores (Bruckmann, 2015; Herrera Santana, 2016; Fornillo, 2016), nos encontramos ante una agudización de esta disputa por los RR.NN., dado el agotamiento o escasez de algunos de ellos, como los yacimientos hidrocarburíferos terrestres (por lo cual se ha venido avanzando hacia los offshore y no convencionales). Ello es producto de diversos factores: el productivismo y consumismo desenfrenado que conlleva el capitalismo global contemporáneo, el ascenso de China e India (los dos países más poblados del mundo y cuyos enormes índices de crecimiento han implicado una gran demanda de fuentes energéticas), y la mentada crisis y transición del sistema mundial, fundamentalmente. Esta creciente competencia por los recursos estratégicos ha revalorizado, a su vez, los espacios geopolíticos, como el sistema Malvinas, Atlántico Sur y Antártida.

Otro elemento geopolítico por señalar constituye el punto de proyección hacia la Antártida que representan las Malvinas. El complejo británico de bases militares en las islas otorga ventajas geopolíticas como "puerta de entrada" y base de reabastecimiento de las expediciones que se dirigen hacia ese continente. Las Georgias y Sandwich del Sur conforman, a su vez, junto a las islas Orcadas y Shetland del Sur la "Convergencia Antártica". Justamente, la Antártida es uno de los dos territorios, junto con las islas Malvinas, que la Argentina mantiene como disputa de soberanía. Nuestro país posee la mayor cantidad de bases permanentes en el "continente blanco", con 6 (al igual que Rusia), y 13 si se cuentan también las de verano (Reino Unido posee 5: 2 permanentes y 3 de verano). A su vez, la Argentina es el único país que cuenta con una presencia antártica ininterrumpida desde 1904, mientras que el Reino Unido instaló allí su primera base en 1943.

Este continente se encuentra bajo tutela del Tratado Antártico, que prohíbe cualquier tipo de exploración o explotación de recursos y cuya prórroga vence en 2041. Sin embargo, el caos sistémico mundial ha llevado a las grandes potencias a no esperar a ello, y la carrera por el acceso a los importantes recursos de la Antártida ya ha comenzado, con el componente tecnocientífico como su principal estímulo. Como consecuencia del 
cambio climático y el deshielo en los polos, las condiciones son más favorables para los desafíos tecnológicos y financieros que implica avanzar sobre esos recursos, y podría habilitarse también una ruta marítima antártica. Se estima que la Antártida contiene, en forma de hielo, más de las tres cuartas partes del agua dulce del mundo, elemento indispensable para la vida humana y sobre el cual ya existen pronósticos que alertan sobre su escasez futura en crecientes regiones del planeta, junto con las posibles guerras que ello podría acarrear. Por otro lado, presenta la Antártida importantes recursos energéticos y biodiversidad de gran valor para la industria farmacéutica.

No debe dejar de señalarse, por otro lado, la proyección con que cuenta el Reino Unido desde Malvinas hacia la plataforma continental argentina, segunda del mundo en extensión y una de las más fértiles de todos los océanos, dotada de una gran riqueza en RR.NN.. Se trata de un área muy poco usufructuada por la Argentina, la cual se ha desarrollado "de espaldas al mar", sin haber terminado de dimensionar el enorme potencial económico con que cuenta en ese territorio (se ha buscado comenzar a subsanar esta situación mediante el programa Pampa Azul -Sala, 2018-, creado en 2015 y reactivado en 2020). Ello encuentra el agravante de que, a raíz de la instalación de la Zona Económica Exclusiva circundante a Malvinas para la explotación pesquera, en 1986, el Reino Unido empezó a consolidar su dispositivo estratégico por medio de la ocupación militar efectiva de toda la zona, lo cual logró cristalizar luego en los Acuerdos de Madrid de 1989 y 1990, sus apéndices en materia pesquera y la Comisión de Pesca del Atlántico Sur (Biangardi Delgado, 2017). Mediante esos acuerdos, la Argentina consentía compartir con el Reino Unido información estratégica sobre los recursos vivos marinos de su Zona Económica Exclusiva, desde entonces y hasta 2005, cuando Néstor Kirchner paralizó la actividad de tal Comisión. También se debe destacar la proyección británica hacia la Patagonia desde las islas del Atlántico Sur ${ }^{2}$ : área dotada de importantes riquezas y cuyo territorio presenta enormes extensiones despobladas que representan sólo un $5 \%$ de la población argentina.

Por todo ello, no es extraño que Malvinas constituya también un enclave militar. Es una de las zonas más militarizadas del mundo: mientras que la población civil ronda las 3000 personas, se encuentran apostados en forma permanente entre 1500 y 2000 militares. El complejo de bases militares de Monte Agradable (Mount Pleasant Complex) es el más importante de toda América Latina y cuesta más de 60 millones de libras anuales mantenerlo. Ello otorga proyección aeronaval en toda la región, lo que permite controlar el tráfico civil y militar que navegue o sobrevuele la zona desde un centro de apoyo militar de rápido despliegue (Vázquez del Faro, 2019; Museo Virtual Malvinas, s.f.). En las últimas décadas, el Reino Unido ha aumentado sistemáticamente su poderío bélico en Malvinas y Georgias, desplegando armamento de última generación. Operan en Malvinas sus tres armas (Real Fuerza Aérea, Marina Real y Ejército Real), y cabe señalar que el Reino Unido constituye una de las cinco principales potencias mundiales en cuanto a sus capacidades militares, en materia nuclear, naval, armamentística, etc. En la Figura 1 se presenta un mapa en el que se visualiza toda esta región en disputa. 
FIGURA 1

Presencia británica en el Atlántico Sur y la Antártida ${ }^{3}$

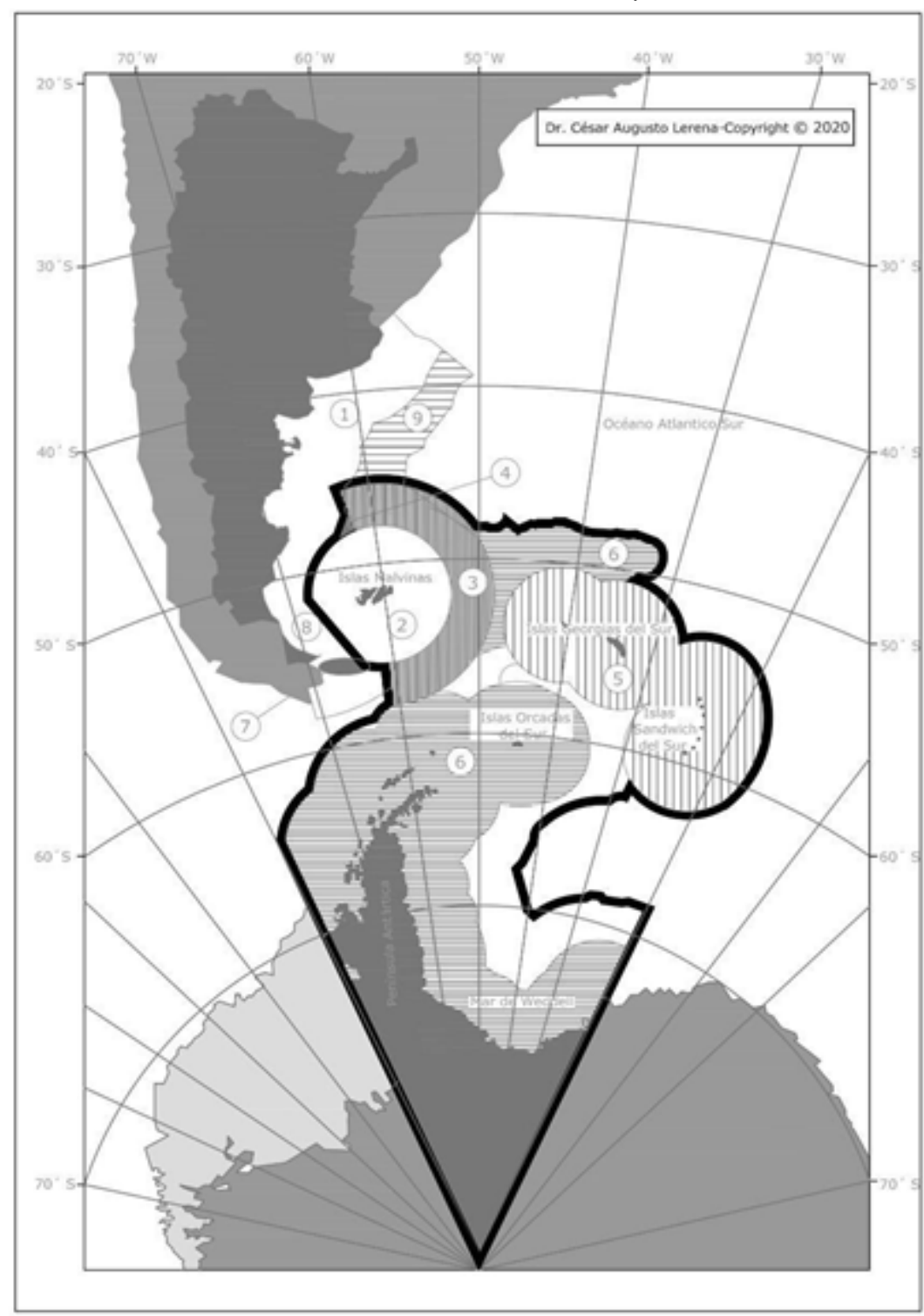

Fuente: Lerena, 2020.

\section{ACERCA DE LOS ACTORES EN DISPUTA Y LA ESCALA DE LOS CONFLiCTOS}

Entrado el siglo XXI, el conflicto por la soberanía de Malvinas, las islas del Atlántico Sur y los espacios marítimos circundantes dejó de ser sólo un problema entre la Argentina y el Reino Unido, y se transformó en una causa regional y global. La mayor gravitación internacional de la Cuestión Malvinas está estrechamente asociada a la política exterior argentina sobre la materia por parte del ciclo de gobiernos kirchneristas, que efectuó un cambio de paradigma (si bien con antecedentes desde el año 2000) con respecto a las políticas de "seducción de los kelpers" y pasaje a segundo plano de la cuestión de la soberanía, pergeñadas bajo la administración Menem-Cavallo-Di Tella. La denuncia sistemática del avance británico en el usufructo de los recursos naturales del Atlántico Sur y los reclamos diplomáticos en foros internacionales para que el Reino Unido acate las resoluciones de la ONU concitaron el apoyo de los distintos organismos de integración regional sur/latinoamericana (Mercado Comn del Sur -MERCOSUR-, Alianza Bolivariana para los 
Pueblos de Nuestra América -ALBA-, UNASUR, CELAC ${ }^{4}$ ) y un conjunto de bloques internacionales: Cumbres de Países Sudamericanos y Africanos, Cumbres Iberoamericanas, Cumbre América del Sur-Países Árabes, Zona de Paz y Cooperación del Atlántico Sur y el Grupo de los 77 más China, entre otros (MREC, 2015). Ya en 2007, países díscolos de la hegemonía occidental, como China, Rusia, Siria e Irán, apoyaron las denuncias del canciller Taiana en el seno de la ONU. A fines de ese año, la Unión Europea pasaba a reconocer como propios los Territorios Británicos de Ultramar en su nueva Constitución (Tratado de Lisboa).

Es cierto que existen antecedentes de esta importante gravitación internacional de la Cuestión Malvinas que se remontan a la resolución 2065 de la ONU en 1965, ante la oleada descolonizadora de la segunda mitad de siglo XX, y la guerra del Atlántico Sur en 1982, la cual contó con una gran solidaridad latinoamericana hacia la posición argentina y una gran ayuda estadounidense a su aliado anglosajón. Sin embargo, la crisis del sistema mundial desatada a fines del siglo XX y principios del XXI profundizó tal gravitación, ante los crecientes procesos de multipolaridad relativa, declive de la hegemonía estadounidense y escalamiento de tensiones entre polos de poder centrales y emergentes (Merino, 2016).

Se debe mencionar en este punto el escalamiento del umbral de poder mundial, ese quantum mínimo necesario por debajo del cual cesa la capacidad autonómica de una unidad política (Gullo, 2015), hacia niveles territoriales crecientes. Ello ayuda a comprender esta transformación de la Cuestión Malvinas de una causa nacional a una también regional y global. Si ya el Estado-nación se hallaba obsoleto en cuanto umbral de poder, a raíz del salto que implicó el desarrollo de los Estados-nación industriales (Gran Bretaña como paradigma, siglos XVIII-XIX), primero, y de los Estados continentales industriales, luego (Estados Unidos como paradigma, siglo XX -Methol Ferré, 2009-), la globalización implicó un nuevo salto. Desde la década de los setenta, con la revolución científico-técnica centrada en el paradigma micro-electrónico, o electroinformático, y las Tecnologías de la Información y la Comunicación, se vislumbra un nuevo escalamiento del umbral de poder. Ello guarda relación con los procesos de transnacionalización del capital, la globalización económica y financiera, y la necesidad de un "contenedor" más amplio para la incesante acumulación sin fin de capital y poder (Arrighi, 2007). De ahí la búsqueda por imponer formas proto globales de institucionalidad jurídico-política afines al capital financiero global (Dierckxsens et al., 2018; Merino y Narodowski, 2019). Una vez hubo comenzado el fin de la Guerra Fría, con la caída del muro de Berlín en 1989, el mundo bipolar iniciaba su tránsito a la -breve- unipolaridad, mientras EE.UU. lanzaba el Consenso de Washington y sus intelectuales orgánicos, el mito del "fin de la historia". Sin embargo, no duraría mucho tal hegemonía globalizadora.

Por todo lo anterior, resulta esencial para los Estados latinoamericanos la integración regional, en pos de la agregación de capacidades para favorecer el desarrollo, y, en consecuencia, fortalecer los procesos autonómicos. Éstos se refieren a la búsqueda por alcanzar la máxima capacidad de decisión propia que un país (o grupo de ellos) puede/ $\mathrm{n}$ poseer, teniendo en cuenta los condicionamientos objetivos del mundo real, por lo cual autonomizar refiere a ampliar los márgenes de maniobra (Briceño Ruiz y Simonoff, 2017).

En este marco, la Cuestión Malvinas, el conflicto de soberanía de más larga data del mundo, se ha vuelto un símbolo para la denuncia de la pervivencia del colonialismo, la depredación y expoliación de los recursos naturales y la creciente militarización del Atlántico Sur por parte del Reino Unido, en alianza con EE.UU. y la OTAN. Los organismos de integración sur/latinoamericana expresaron, con sus alcances y limitaciones, el carácter estratégico de la defensa de los intereses regionales y nacionales en esa zona, mientras que los polos de poder emergentes y alternativos visualizaban la relevancia estratégica creciente del enclave que representa Malvinas, y la riqueza de los espacios marítimos del Atlántico Sur y del continente antártico.

\section{BREXIT: DISPUTA INTESTINA Y PERSPECTIVAS SOBRE EL FUTURO ROL MUNDIAL BRITÁNICO}

El 23 de junio de 2016 se llevó a cabo el referéndum consultivo para decidir la salida o permanencia del Reino Unido de la Unión Europea, en el cual la posición de salida se impuso ajustadamente (52 a 48 \%). El 
Brexit representó un acontecimiento de primer orden en la geopolítica mundial, leído como la primera resistencia seria y en pleno centro del mundo al proceso de globalización (Bilmes, 2018).

Este nacionalismo británico antieuropeísta no era algo nuevo, sino que encontraba importantes raíces en la idea de la "excepcionalidad inglesa" (Escocia se hallaba al margen de ello, como en el proceso actual), nacida al calor de la ruptura del rey Enrique VIII con Roma y la creación del anglicanismo en el siglo XVI (Ramos, 2019). Si bien el Reino Unido se integró a la Comunidad Económica Europea en 1973 (agrupamiento que nació luego de la Segunda Guerra Mundial, a instancias de la iniciativa franco-germana), los británicos han mantenido un rol excepcional en el bloque. Así, nunca se unió al Tratado de Schengen, de libre circulación de personas en territorio europeo (firmado en 1985), mientras que ante el Tratado de Maastricht que dio nacimiento a la Unión Europea, en 1993, se unió al mercado común, pero conservando su moneda, la libra esterlina. Luego, ante la oleada de "euroescepticismo" que recorrió la Unión Europea al calor del impacto de la crisis financiera global en su territorio, hacia 2009-2012, y el ahogo desplegado por el núcleo de conducción germano-francés sobre las periferias europeas ante las crisis de deuda, los brexiters vieron su oportunidad. Así, los sectores políticos y sociales que renegaban de la integración británica a Europa aprovecharon para imponer la realización del referéndum. Este conjunto de fuerzas se ha coaligado detrás de las banderas de "volver a tomar el control", en referencia a la capacidad de definir políticas migratorias, laborales, sanitarias, educativas, etc., frente a lo que se percibía como una pérdida de soberanía con respecto a Bruselas (capital política de la Unión Europea).

De este modo, según la lectura que aquí se sostiene, ante las crecientes fracturas en los bloques de poder occidentales a raíz de la crisis y transición del sistema mundial, el nacionalismo conservador británico que ha impulsado el Brexit busca recuperar grados de soberanía y margen de maniobra geoestratégica, según esta visión geopolítica, enfrentado tanto con el núcleo de conducción germano-francés de la UE como con las fuerzas globalistas con fuerte peso en la city de Londres, nodo fundamental del capital financiero global ${ }^{5}$. Esto último se refiere a la disputa intestina existente dentro del Reino Unido entre los actores que han venido impulsando el proceso de globalización y financiarización y aquellos que se ven perjudicados por tal proceso. Se entienden así los posicionamientos ante la votación del Brexit: contrarios a él las mayores bancas, empresas, medios de comunicación, centros de ideas, políticos afines, tanto "por izquierda" como "por derecha", y favorables amplias capas de trabajadores junto con sectores del poder económico, político y mediático más conservadores y nacionalistas ${ }^{6}$.

Se debe señalar también el tendencial declive geoeconómico británico, ante el desplazamiento en curso del "centro de gravedad" de la economía -y el poder- mundial desde el Atlántico Norte hacia Asia-Pacífico. Según datos del Banco Mundial, a 2016 el Reino Unido se ubicaba en el quinto lugar según su producto bruto interno -PBI- nominal (luego de EE.UU., China, Japón y Alemania), pero en el noveno lugar si se medía por valores de paridad de poder adquisitivo -PPA-, siendo superado en esta medición por India, Rusia, Brasil e Indonesia. Los análisis prospectivos de los organismos internacionales y las principales usinas de pensamiento identifican ya desde principios de siglo este auge de las "economías emergentes", motorizado principalmente por el enorme crecimiento desde hace décadas de China e India. Tales tendencias geoeconómicas parecían desfavorables para la histórica primacía británica (y también angloamericana y occidental) de no mediar grandes cambios. Ello se sumaba al importante déficit comercial británico (durante 2019 se situó en 197.000.000.000 de euros, siendo hacia 2015 el país con mayor déficit en el comercio intra$\mathrm{UE)}$, que dificultaba los equilibrios macroeconómicos, y, sobre todo, demostraba su retraso en el mercado europeo en la competencia por desarrollar productos de mayor complejidad y contenido tecnológico. En este marco, el Brexit resultó una de las formas de "patear el tablero" por parte del establishment británico en pos de sostener las bases de su poderío.

El Reino Unido entró en una profunda crisis política a causa de las disputas en torno a su salida de la Unión Europea, una situación que bien podía ser caracterizada de acuerdo con la fórmula gramsciana de empate hegemónico; esto es: cada grupo social en pugna tenía la suficiente fuerza como para vetar los proyectos 
elaborados por los otros, pero ninguno lograba reunir las fuerzas necesarias para dirigir el país del modo deseado. Ello se evidenció en la sucesión de gobiernos del Partido Conservador (tories) que no pudieron sortear las disputas intestinas de su propio partido, y en el país en su conjunto, para definir un rumbo en torno a la salida (o no) de la UE. El primer ministro Boris Johnson, el político más similar a Donald Trump en cuanto a sus posturas radicalmente nacionalistas, antieuropeas y antiglobalistas, logró sortear esta crisis política y este empate hegemónico británico, y alcanzó un acuerdo parlamentario y el apoyo de la reina Isabel II para solicitar formalmente la salida británica de la Unión Europea el 31 de enero de 2020.

Más allá de estas disputas políticas internas, y como uno de los trasfondos de las pujas de poder de todo este proceso, se han puesto de manifiesto las pretensiones de una fracción del poder británico de efectuar un realineamiento geopolítico del Reino Unido, buscando asumir un nuevo lugar en la economía y política mundial pos Brexit. El lema tory "Global Britain” ("Gran Bretaña Global”) que se puede observar en las declaraciones y publicaciones gubernamentales (HM Government, 2018a) expresa estas pretensiones y este horizonte. Según documentos gubernamentales que revisan la estrategia nacional de seguridad de 2010, ello significa un "poder global que juega un papel de liderazgo en el escenario mundial" (HM Government, 2018b). Esto comprende, también, un componente expansionista, como se puede apreciar en el segundo epígrafe de este trabajo, en el discurso del entonces Secretario de Defensa británico Williamson (2019), a fines de 2018. Se habló en ese entonces del establecimiento de dos nuevas bases militares británicas, que podrían emplazarse en el sudeste asiático y en el Caribe.

En ese marco, aparecen opciones abiertas para el nuevo papel mundial británico. Por un lado, se encuentra la perspectiva de estrechar la alianza estratégica con EE.UU., con quien comparte raíces culturales anglosajonas. Se trata de una relación muy cercana, con antecedentes desde principios del siglo XX y cristalizada como tal desde la Carta del Atlántico de 1941, en plena guerra mundial, la cual estableció una asociación transatlántica entre ambos países (y fue, además, un antecedente para la creación de la OTAN en 1949 y la alianza de inteligencia anglosajona de los "cinco ojos" luego -Meyssan, 2016-). De hecho, los documentos oficiales reconocen a EE.UU. como la "asociación estratégica más vital" de su nación, y sobre la cual llaman a profundizar sus lazos en materia comercial (UK Parliament, 2018). En un momento en que ambos países se encontraban conducidos por proyectos político-estratégicos nacionalistas conservadores y antiglobalistas, se avanzó en la búsqueda de establecer un gran acuerdo de libre comercio entre ellos. Sin embargo, la victoria de Biden en 2020 en EE.UU. puede poner un freno a estas perspectivas.

Por otro lado, el nacionalismo conservador británico ha entablado hace algunos años una relación muy cercana con China, estrechando las profundas interconexiones entre ambos países existentes desde las "guerras del opio" del siglo XIX. Desde 2013 comenzaron a manifestarse pretensiones de firmar un Tratado de Libre Comercio entre ambas partes, mientras que en 2015 el Reino Unido aparecía como el primer miembro del G-7 en asociarse al estratégico Banco Asiático de Inversión en Infraestructura, puntal de la propuesta de nueva arquitectura financiera mundial propuesta por China (Jalife-Rahme, 2015). A la par, ambos venían entablando firmas de tratados y acuerdos de cooperación (como la "abarcadora alianza estratégica para el siglo XXI” en 2015), por lo cual la entonces primera ministra Theresa May calificó las relaciones entre ambos países como "doradas" ante la llegada del primer tren chino a Londres, parte de la "Nueva Ruta de la Seda".

Aquella aparente oscilación británica entre su acercamiento a su aliado anglosajón (que fue primero su colonia, independizada en 1776, y desde las dos guerras mundiales del siglo XX desplazó a Gran Bretaña como potencia hegemónica del mundo occidental) y su nuevo aliado oriental, potencia económica en ascenso, puede ser leído como una clásica jugada geopolítica británica "a dos puntas" (Jalife-Rahme, 2016), manteniendo un pie en la alianza noratlántica que conduce EE.UU. mientras quita su otro pie de Europa para colocarlo en China e India. Sin embargo, durante 2020 Johnson se plegó a la campaña antichina de Trump en ciertos temas (5G, Hong Kong, entre otros.), con lo que puso cierto freno a este acercamiento. 
Mientras tanto, lo central para las pretensiones nacionalistas británicas constituye su propia proyección de poder en pos de vigorizar sus complejos exportadores, industrial-militar y científico-tecnológico sobre otros territorios, para conservar su rol de "jugador global" ante la transición geopolítica de este siglo XXI, apuntando a sus históricas esferas de influencia ${ }^{7}$. He ahí el rol esencial de los 14 Territorios Británicos de Ultramar (BOT por sus siglas en inglés: British Overseas Territories), las dependencias de la Corona Británica (Crown Dependencies), y la Mancomunidad de Naciones (Commonwealth), como se puede apreciar en la Figura 2:

FIGURA 2

Urdimbre institucional del Reino Unido y sus vestigios coloniales

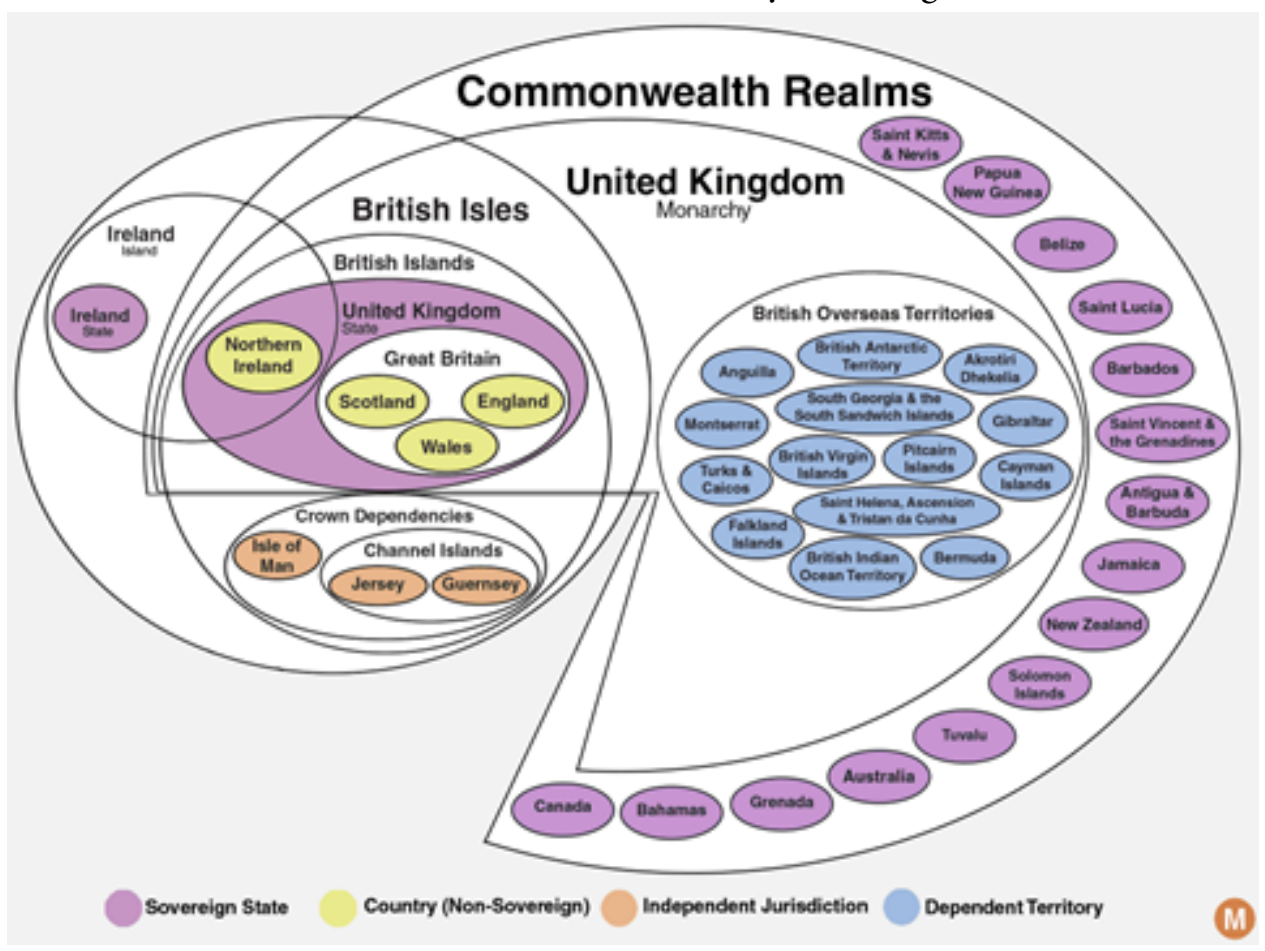

\footnotetext{
Nota: En color violeta figuran los Estados soberanos; en dorado, los países (no soberanos) pertenecientes al Estado Reino Unido; en color salmón, las dependencias de la Corona ("jurisdicciones independientes") y en celeste los BOT ("territorios dependientes"). Fuente: Metrocosm. Disponible en https://i0.wp.com/metrocosm .com/wp-content/uploads/2016/06/commonwealth-realms-6.png
}

En cuanto a los BOT, se trata de territorios no incorporados bajo jurisdicción y soberanía del Reino Unido, que reconocen a la monarca británica como jefa de Estado. Salvo los territorios sin población permanente, cuentan con diversos grados de autonomía interna, y al menos la defensa y las relaciones internacionales son responsabilidad del gobierno británico mediante el Foreign and Commonwealth Office. En el documento gubernamental de 2012, denominado "Libro Blanco de los Territorios de Ultramar", se definía el carácter estratégico que éstos presentan para el Reino Unido y la voluntad de fortalecer los vínculos con ellos, a todo nivel (Foreign and Commonwealth Office, 2012). Las posesiones en toda la zona del Atlántico Sur representan activos estratégicos para las perspectivas británicas, como reconocen tanto sus sectores militares y políticos como los académicos (Dodd, 2012). En la Figura 3 se puede apreciar el "collar de perlas" con que cuenta el Reino Unido en el Atlántico Sur (De los Reyes, 2016): isla Ascensión (compartida con EE.UU.); islas Santa Helena y Tristán da Cunha; Malvinas; Georgias del Sur y Sandwich del Sur; y Sector Antártico Británico. 
FIGURA 3

Territorios Británicos de Ultramar

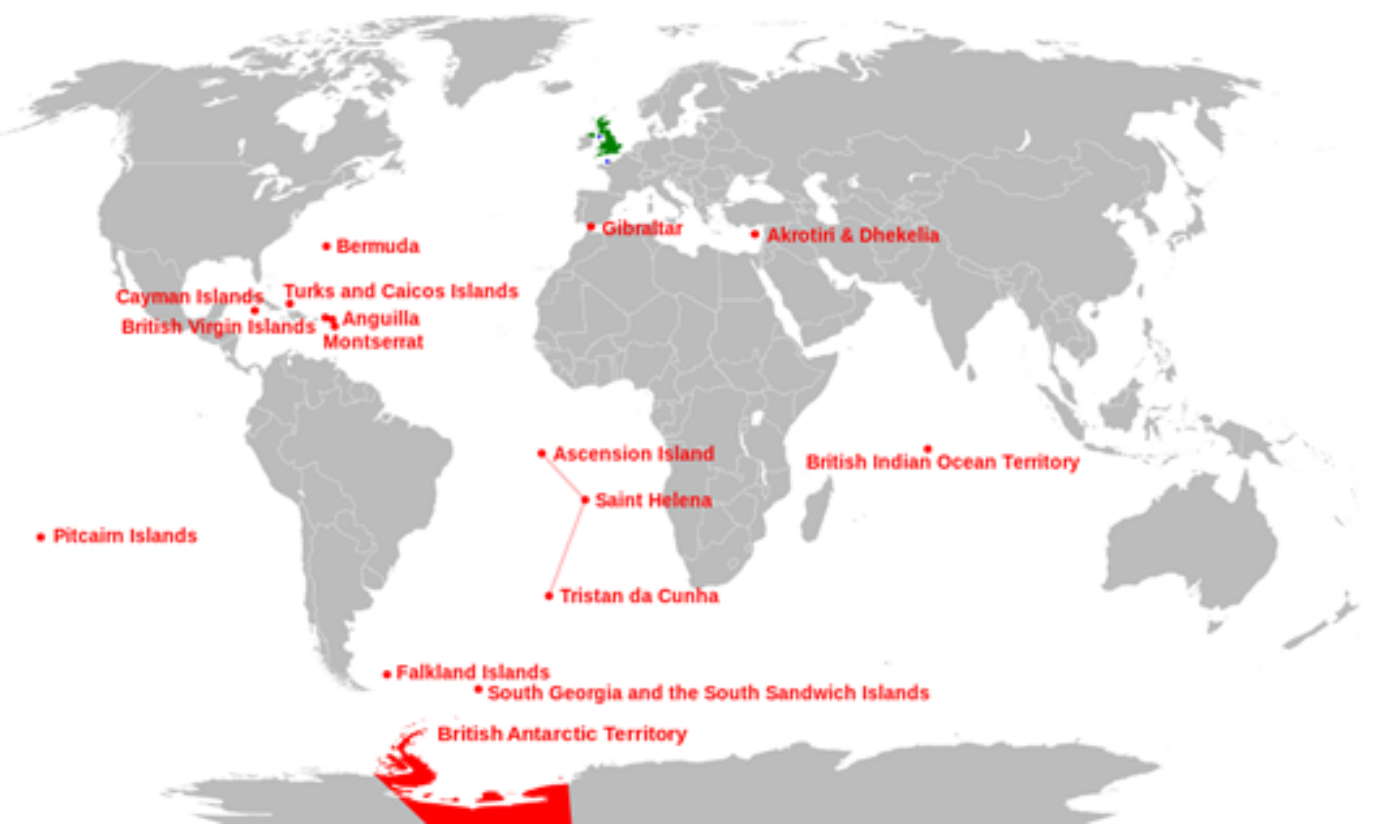

Fuente: Mapas Owje. Disponible en http://mapas.owje.com/maps/10917_territorios-britanicos-de-ultramar.html

Por otro lado, la Mancomunidad de Naciones consta de 54 países en todos los continentes, que agrupan un tercio de la población mundial (2400 millones de personas) y comprenden un $25 \%$ del comercio internacional. Si bien muchas de esas naciones fueron descolonizadas después de Bretton Woods, siguen sosteniendo a la reina Isabel II del Reino Unido como cabeza de la organización. La habilidad de la diplomacia británica ha llevado a que lo que había sido una organización nucleada en torno a un imperio colonial se adaptara a los nuevos tiempos y se redefiniera, con flexibilidad y pragmatismo, como una asociación (Esteban, 2017).

Se puede apreciar una apuesta británica por la Commonwealth luego del referéndum de 2016, con crecientes avances. No se trata de un secreto, sino que los mismos documentos gubernamentales de política exterior denominan a la Mancomunidad como una "red global única" de carácter estratégico para el Reino Unido (HM Government, 2018c). Ello se pudo observar con claridad en la Cumbre de Jefes de Gobierno de la organización en abril de 2018, realizada en Londres y en la que se firmó un conjunto de acuerdos de cooperación que preveían cuadriplicar el comercio intra bloque, de 560.000.000.000 de dólares en la actualidad a 2.000.000.000.000 para 2030 (The Commonwealth, 2018a).

La proyección estratégica del Reino Unido pos Brexit sobre la Commonwealth se basa en una serie de ventajas para el nuevo rol global que aspira a desempeñar el nacionalismo británico, entre las cuales sobresale el idioma (inglés) y el sistema legal (de raíz británico) común a muchos de estos países, junto con el poderío británico en $\mathrm{I}+\mathrm{D}+\mathrm{i}$ (Investigación, desarrollo e innovación) en materia científico-tecnológica \#claramente el de mayor fuerza del bloque y ya sin la competencia de otros jugadores de primer nivel, como Alemania en la UE\#. Un dato fundamental para estas perspectivas británicas de despliegue de su poderío exportador, industrial-militar y científico-tecnológico sobre la Commonwealth está dado en la participación del bloque en el PIB mundial, en comparación con el de la Eurozona: si en 1970 esta última se encontraba por encima del $20 \%$ y el primero en $10 \%$, hacia 2009 ambos convergen, y en 2016 ya se invierte la tendencia, habiendo bajado al $15 \%$ los europeos mientras que la Mancomunidad se encontraba arañando el $20 \%$ (GEAB, 2018). Ello está en concordancia con la tendencia de desplazamiento del centro de la economía mundial hacia "economías emergentes" con eje en Asia-Pacífico, desde la crisis de acumulación y hegemonía de los años setenta del siglo $\mathrm{XX}$. 
Cabe señalar, sin embargo, que se trata de un grupo heterogéneo el de las naciones pertenecientes a la Mancomunidad. Por ejemplo, algunas de ellas son miembros históricos en la proyección geopolítica unipolar de la "angloesfera", como Canadá, Australia y Nueva Zelanda, mientras que otras tienen un juego geopolítico particular, como el caso de India: esta pivotea entre su pertenencia al BRICS (bloque que ha mermado en su rol pujante en los últimos años) y a la Organización de Cooperación de Shanghái, y su pertenencia al Diálogo de Cooperación Cuadrilateral junto a EE.UU., Japón y Australia, cooperando con la estrategia occidental de contención de China en el sudeste asiático. Por ello, se proyecta a futuro una disputa por el control sobre esos territorios, en cuanto a cooperación internacional, comercio e inversiones, que representa una prioridad fundamental para el nacionalismo imperial británico después del Brexit.

\section{ImPaCto POTENCIAL DEL Brexit Sobre Malvinas: ¿OPORTUNIDAD o AMENAZA?}

Existe desde 2016 todo un debate acerca de si el Brexit representa una oportunidad o una amenaza para la posición argentina y suramericana. Presentaremos aquí, sintéticamente, algunas aristas de los posibles impactos e implicancias de la salida británica del bloque europeo sobre la Cuestión Malvinas.

\section{Oportunidades}

A pesar del lobby y las presiones ejercidas por las autoridades de los BOT a lo largo de los años de negociaciones entre europeos y británicos, su expresa exclusión del Acuerdo de Salida representó un fuerte golpe, que despertó una reacción de "decepción y frustración” en el gobierno de ocupación de Malvinas (Penguin News, 2021). Las razones de tal malestar tienen un claro trasfondo económico. Las principales actividades económicas isleñas son fuertemente dependientes del Mercado Común Europeo: en el caso de la pesca, que representa el $60 \%$ del PIB isleño, más del $90 \%$ de sus exportaciones tiene como destino ese mercado, mientras que cerca del $50 \%$ de la carne ovina, su segunda mayor actividad, se destina a la UE (Falkland Islands Gov., 2019).

La exclusión del Acuerdo implicaría que estas exportaciones pierdan la exención de cuotas y aranceles, y pasen a quedar sujetas desde inicios de 2021 a las tarifas de la Organización Mundial del Comercio (OMC): entre $6 \%$ y $18 \%$ para los productos pesqueros y $42 \%$ para la carne. Según ciertas estimaciones, esto podría implicar una caída de más de 10.000.000 de libras anuales en ingresos para las islas, dado que casi el $75 \%$ del PIB isleño depende del acceso al Mercado Común Europeo (Embajada Abierta, 2021).

No obstante, se ha señalado que se podrían sortear estas medidas mediante la utilización de ciertos vacíos legales en el gobierno de ocupación isleño, como el cambio de bandera de los buques pertenecientes a las joint ventures anglo-españolas, que pasarían a usar la bandera española para ingresar a la UE, sobre todo a través del puerto de Vigo, punto de ingreso del $95 \%$ de los productos pesqueros de la zona de Malvinas (Ortega et al., 2019; Lerena, 2021).

Por otro lado, el comercio entre Malvinas y el mercado europeo sufriría mayores costos de comercialización, crecerían las trabas y demoras en los puertos de acceso, se perdería competitividad, y, por ende, también empleos en las islas y en Europa. Otra pérdida importante para las islas es el acceso al financiamiento para el desarrollo que la UE destina a sus territorios de ultramar, como el Fondo de Desarrollo Económico Europeo (por el cual recibieron casi 6.000.000 de euros como apoyo presupuestario en 2014-2018), el programa BEST, de protección de ecosistemas (por el cual Malvinas recibió unos 600.000 euros en años recientes), $\mathrm{u}$ otros como los programas de financiamiento en ciencia, tecnología e innovación (Horizon 2020) y de movilidad estudiantil (Erasmus+).

Previendo tales situaciones, las autoridades gubernamentales del Reino Unido y de Malvinas han ido diseñando políticas para contrarrestar tales consecuencias. Sobresale entre ellas el anuncio del gobierno 
británico, en 2019 y con miras a tranquilizar las preocupaciones de los isleños, de que sostendría y se haría cargo del financiamiento para sus territorios de ultramar de los proyectos de desarrollo mencionados, y la igualdad de condiciones para acceder a la UE a ciudadanos de los BOT con respecto a ciudadanos británicos (Mercopress, 2019). Se trata de cargas financieras importantes para una economía como la británica, que se cuenta entre las más afectadas del mundo por la pandemia de COVID-19, con un derrumbe histórico de 10 $\%$ de su PIB en 2020, y que venía golpeada ya desde la crisis financiera global de 2008.

A su vez, en materia política y diplomática, la posición británica sobre Malvinas, y sus BOT en general, se ha visto debilitada en ciertos puntos. Ello se puede observar en la falta de apoyo de los países europeos al Reino Unido ante la ONU en su conflicto con Mauricio respecto de las islas Chagos, archipiélago de más de 50 islas en el Océano Índico que la República de Mauricio reclama como parte de su territorio y que tiene una afinidad con el caso de Malvinas. Se encuentra ubicada en tal archipiélago la isla Diego García, que constituye un punto geoestratégico en el Océano Índico y que había sido cedida en 1966 por el Reino Unido a su socio estadounidense para que instalase allí una base militar, previa expulsión de la población nativa. La Corte Internacional de Justicia (CIJ) se pronunció en febrero de 2019, mediante una opinión consultiva, a favor de la devolución de tal archipiélago a Mauricio (ese mismo mes la UE publicaba un documento que calificaba a Gibraltar como una colonia británica). En mayo de ese año, la Asamblea General (AG) de la ONU aprobó una resolución en la que insta al gobierno británico a retirarse de Chagos en un lapso de 6 meses, lo que denotaba un quiebre en el histórico alineamiento del bloque europeo. Al mes siguiente, el gobierno británico desconoció el fallo y afirmó que continuaría con la administración.

Un año más tarde, en junio de 2020, se produjo un hecho por demás relevante e inesperado: un grupo de 30 parlamentarios ingleses de distintos bloques presentó una carta al primer ministro, exhortándolo a respetar lo establecido por las instancias de la ONU sobre la devolución del archipiélago de Chagos a Mauricio (UK Parliament, 2020). Se expresa en la carta que la no aceptación de la CIJ y la AG dañaría la credibilidad internacional británica, y que si se quiere lograr una Gran Bretaña Global se debe demostrar el apego a la legalidad internacional y el respeto de los derechos humanos.

Se suma a ello la pérdida del juez británico en la CIJ, siendo la primera vez en la historia que un miembro permanente del Consejo de Seguridad de la ONU no cuenta con un magistrado de su nacionalidad en la Corte de la Haya, y la facultad de veto que otorgó la UE a España en toda decisión relativa a Gibraltar mientras se negociaba el Acuerdo de Salida, a la par que otorgó voz y voto al peñón en esas negociaciones.

Como se puede apreciar en estos hechos, constituyen oportunidades para la posición argentina y suramericana las fracturas en los bloques de poder occidentales que se producen en este marco de caos sistémico y transición geopolítica mundial. Aunque, claro está, ello puede ser aprovechado sólo si se logra desplegar desde el lado argentino toda una política integral en la materia (exterior, diplomática, legislativa, económica, tecnocientífica, cultural, etc.) para construir escenarios favorables. En este sentido, se ha comenzado a buscar un acercamiento con la Unión Europea para negociar su apoyo diplomático al reclamo argentino por Malvinas, como también el restablecimiento de alianzas internacionales con China, Rusia y demás actores que pujan por acrecentar la situación de multipolaridad relativa, junto con una política de presión no sólo diplomática sino también económica para obstaculizar los negocios británicos en el Atlántico Sur, aprovechando los posibles impactos económicos adversos que se han detallado.

\section{Amenazas}

Por el lado de las amenazas para la posición argentina y suramericana, aparece en primer lugar el giro nacionalista, territorialista y expansionista británico que ha sido descrito. El sistema Malvinas, Atlántico Sur y Antártida representa una zona de carácter estratégico para la proyección de poder -actual y futura- del Reino Unido. 
Un escenario posible es la independización formal de Malvinas para constituir las islas como un Estado independiente, Falklands, que pudiera integrarse como nación soberana a la Commonwealth, bajo protección militar británica (Lualdi, 2019). Aparecían indicios de esa posibilidad en años recientes, a raíz de la estrategia británica para hacer frente a la ofensiva diplomática argentina por la soberanía sobre Malvinas en la primera década y media del siglo XXI. En efecto, con base en sus usos e interpretaciones del derecho a la autodeterminación de los pueblos (en clara contradicción con el abordaje que realizan en el mencionado caso de Chagos), el Reino Unido impulsó el ilegítimo referéndum "kelper" de 2013, que plebiscitaba si se deseaba conservar el estatus político de Territorio Británico de Ultramar, lo que se impuso casi por unanimidad. Ello se sumaba a la "Orden de la Constitución de las Islas Falklands 2008”, definida por la monarca británica. Tales factores podrían dar indicios de una búsqueda por sentar las bases jurídicas y políticas para la constitución de ese Estado independiente. Este escenario podría encontrar condiciones de posibilidad a futuro, ante el creciente papel de la Mancomunidad en la proyección de poder global británica a que se ha hecho referencia.

En el "Libro Blanco" se expresan consideraciones sobre este tipo de posibilidad. Se afirma en él que "donde la independencia es una opción y es el deseo ${ }^{8}$ claro y constitucionalmente expresado del pueblo de buscar la independencia, el Gobierno del Reino Unido cumplirá con sus obligaciones de ayudar al Territorio a lograrlo" (Foreign and Commonwealth Office, 2012, p. 15). En caso de que la economía isleña avanzara en su autonomía financiera, a través del desarrollo pesquero, hidrocarburífero y del resto de sus abundantes recursos, esta posibilidad podría tomar mayor carnadura. Aunque se presenta éste como un escenario complejo, no debería dejar de tomarse en consideración a futuro.

Por otro lado, se debe señalar también que, en el marco de la apuesta británica por fortalecer la Commonwealth, se ha venido desplegando una política de mostrarse receptivos y líderes de la transición energética global en curso, en favor de fuentes renovables y no contaminantes del ambiente y del cuidado de este último. En ese marco se lanzó la denominada "Carta Azul de la Commonwealth" (2018b), anunciada como un compromiso para proteger y gestionar de forma sostenible los océanos. El peligro radica, en este punto, en que, mediante esta iniciativa e instrumento, el Reino Unido buscaría dotar de legitimidad su control sobre los espacios marítimos del Atlántico Sur y el Océano Antártico. En este sentido, en 2016 había dado a conocer lo que denominó "Blue Belt" (Cinturón Azul), que buscaba trazar una zona de exclusividad de 4 millones de $\mathrm{km}^{2}$ entre Malvinas, Georgias del Sur, Sandwich del Sur y el territorio antártico. Cuatro años antes, en 2012, de forma también unilateral y evadiendo el marco de la Convención para la Conservación de Recursos Vivos Marinos Antárticos (que es parte del Sistema del Tratado Antártico), el Reino Unido había creado un Área Marítima de Protección alrededor de las islas Georgias del Sur y Sandwich del Sur, que abarca más de 1.000.000 de $\mathrm{km}^{2}$ y buscaba proteger la riqueza en biodiversidad de la región. De este modo, mediante argumentos "políticamente correctos" busca ocultar sus intereses geoestratégicos en la región. Frente a ello resultan fundamentales, por el lado argentino, iniciativas que avancen en la soberanía efectiva de todo el complejo sistémico Malvinas, Atlántico Sur y Antártida a través de la investigación científica con fines de protección y uso responsable del ambiente, buscando impedir aquella proyección británica. La creación del Área Marina Protegida Namuncurá-Banco Burdwood, en 2013, en el sur del Mar Argentino, y la iniciativa Pampa Azul, en 2015, se inscriben en este marco y se vislumbran como fundamentales sus roles a futuro.

En último lugar, se debe señalar que, en todo el marco de posibles impactos económicos adversos del Brexit con respecto a Malvinas que se describía anteriormente, cobró una gran importancia para el Reino Unido reestablecer una buena relación con la Argentina. Un conjunto de acuerdos bilaterales de carácter desmalvinizador ${ }^{9}$ entre ambos países ha constituido una necesidad estratégica británica en el Atlántico Sur, lo cual se logró en el período 2016-2019, en asociación con el gobierno argentino de Macri, en una serie de actividades: restablecimiento de la cooperación en materia de pesca, hidrocarburos, comercio y navegación; apertura de vuelos comerciales a las islas; cooperación científica en la Antártida; abandono del control aéreo argentino sobre el Atlántico Sur a través de radares; intento de adjudicación de áreas 
offshore hidrocarburíferas de la Plataforma Continental Argentina a empresas ligadas a intereses británicos, fundamentalmente y entre otras (Sánchez, 2018).

\section{REFLEXIONES FINALES: DESAFÍOS PARA LA SOBERANÍA INTEGRAL}

El gobierno de Alberto Fernández ha revitalizado, desde su asunción, el histórico reclamo de soberanía argentino en torno a la Cuestión Malvinas. Se ha comenzado a avanzar en importantes medidas con miras a la constitución de una política de Estado: conformación de un Consejo Nacional asesor en la materia, demarcación de los límites de la Plataforma Continental Argentina (a tono con la presentación argentina ante la Convención de las Naciones Unidas sobre el Derecho del Mar, que fue recomendada en 2016), endurecimiento de sanciones a la pesca ilegal en los espacios marítimos argentinos, suspensión de las investigaciones pesqueras conjuntas en el Atlántico Sur, reimpulso a la iniciativa interministerial Pampa Azul, fundamentalmente y entre otras ${ }^{10}$.

La situación actual en que ha colocado la pandemia de COVID-19 al mundo es muy delicada, pero, como toda crisis, abre también una oportunidad. En este caso, la oportunidad de afianzar la presencia del Estado nacional, como representación de la colectividad, en áreas estratégicas para la vida común, con el fin de hacer frente a los nuevos peligros y amenazas que asedian a la humanidad. En este marco, y en un mundo que profundiza su caos sistémico y las disputas por la reconfiguración de su ordenamiento, se hace patente la necesidad imperiosa de sostener y fortalecer el reclamo soberano argentino sobre el sistema Malvinas, Atlántico Sur y Antártida. Para ello resultará fundamental, en el frente externo, recuperar el estatus de Malvinas como una causa regional y global, en el marco de una política exterior altiva y soberana. La situación de multipolaridad relativa y declive angloamericano y occidental constituye todo un factor por demás favorable para ello, por lo que puede apuntarse, nuevamente, a contar con los respaldos para el reclamo diplomático por parte de polos de poder mundial de signo multipolar.

Por su lado, en el frente interno, proyectar la recuperación de la soberanía argentina sobre Malvinas, Georgias del Sur, Sandwich del Sur y los espacios marítimos circundantes implica toda una estrategia mayor para revertir los mecanismos de dependencia respecto de las grandes potencias y los intereses transnacionales, en la búsqueda por ampliar los márgenes de autonomía y fortalecer los resortes de poder nacionales. Ello demanda una concepción integral de la soberanía, de carácter multidimensional. Se pueden mencionar, sintéticamente y para señalar ciertos trazos gruesos en este sentido, las siguientes aristas:

En materia política, es preciso contar con una amplia coalición de fuerzas políticas y sociales que respalden las necesarias políticas efectivas de recuperación del poder y desarrollo nacional, así como de defensa soberana, bajo una estrategia nacionalista productivista de un proyecto "nacional y popular" lo más amplio posible.

En materia tecno-económica, es imprescindible la recuperación de capacidades estatales para hacer frente al despliegue británico y de otras potencias en el Mar Argentino, la Patagonia, el Atlántico Sur y la Antártida: marina mercante, astilleros navales, medios aeronavales, radares, industria para la defensa y otros sectores que brinden instrumentos que posibiliten desplegar control, supervisión y regulación de las regiones más descuidadas del territorio nacional.

En materia cultural, se advierte la necesidad de difundir e instalar en la población (sectores populares, académicos, científicos, gremiales, educativos, políticos, etc.) una identidad nacional de país marítimo, bicontinental y antártico; situado, pensado y proyectado desde el Sur: regional, global y austral (Recce, 2012; Patronelli, 2017).

En todo este marco, y según se ha señalado, el Brexit puede representar tanto una oportunidad como una amenaza para la posición argentina y suramericana, lo que depende fundamentalmente de las políticas con que se le haga frente. Una posible fórmula para ello podría consistir en "arte de la diplomacia más resortes de poder". Aparecen escenarios complejos, en un mundo en profunda y creciente crisis, descomposición y reconfiguración, pero que a su vez pueden generar un margen para la recuperación de una estrategia de unidad 
continental suramericana, en pos de constituir el umbral de poder necesario para hacer frente a los desafíos del siglo XXI, y de recuperación de capacidades nacionales con miras a la soberanía integral. Todo ello puede ir cimentando el camino para forzar al Reino Unido a volver a las mesas de negociación y acatar las resoluciones de la ONU que lo conminan a desprenderse de sus dependencias coloniales.

\section{Agradecimientos}

Se agradecen los comentarios del evaluador anónimo, y también los de los/as colegas del Proyecto de Investigación de la UNLP (H822) sobre geopolítica del Atlántico Sur y del Equipo de Investigación sobre la Cuestión Malvinas (EdICMa) a versiones previas de este trabajo. Cualquier error u omisión es exclusiva responsabilidad del autor.

\section{REFERENCIAS}

Arrighi, G. (2007). Adam Smith en Pekin. Origenes y fundamentos del siglo XXI. Madrid: Akal.

Bernal, F. (2011). Malvinas y petróleo. Una historia de piratas. Bs. As.: Capital intelectual.

Biangardi Delgado, C. A. (2017). Cuestión Malvinas. A 35 años de la guerra del Atlántico Sur. Propuesta para la construcción de una Politica de Estado. Bs. As.: Dunken.

Bilmes, J. (octubre 2018). Brexit, Trump y laprofundización de la crisis mundial:pujas depoder yperspectivas geopoliticas. I Jornadas Platenses de Geografía, 17 al 19 de octubre de 2018, La Plata, Argentina. Universidad Nacional de La Plata. Facultad de Humanidades y Ciencias de la Educación. Departamento de Geografía. Disponible en: http: //www.memoria.fahce.unlp.edu.ar/trab_eventos/ev.11243/ev.11243.pdf

Bilmes, J., Dubin, M. y Liaudat, S. (2020). Pandemia o la continuación de la guerra por otros medios. En U. Bosia y E. Ivanis (Comps.), Sopa de carpincho: ideas a un metro de distancia (pp. 99-104). Buenos Aires: Instituto Democracia.

Briceño Ruiz, J. y Simonoff, A. (2017). La Escuela de la Autonomía, América Latina y la teoría de las relaciones internacionales. Estudios Internacionales $\mathrm{N}^{\circ} 186,39-89$.

Brown, D. (1987). The Royal Navy and the Falklands War. Londres: Pen \& Sword Books.

Bruckmann, M. (2015). Recursos naturales y la geopolitica de la integración sudamericana. Buenos Aires: LuxemburgImago Mundi.

Cangiano, F. (2019). Malvinas. La cultura de la derrota y sus mitos. Bs. As.: Dunken.

Caplan, S. y Eissa, S. (2015). Análisis estratégico del Sistema Malvinas, Antártida y Atlántico Sur. Documentos de Trabajo No 28. Buenos Aires: Escuela de Defensa Nacional.

Cisilino, J. (2020). Territorio, Geopolitica y Soberania: la Cuestión Malvinas en los discursos presidenciales (1982-2020). Inédito. UNLP, Argentina.

De los Reyes, M. (2016). El collar de perlas británico en el Atlántico Sur. Una amenaza a la seguridad regional. Sociedad Argentina de Estudios Estratégicos y Globales. Recuperado de http://saeeg.org/index.php/2016/04/16/el-collar -de-perlas-britanico-en-el-atlantico-sur-una-amenaza-la-seguridad-regional/

Dierckxsens, W., Formento, W., Bilmes, J., Barrenengoa, A., Del Negro, L. y Schulz, S. (2018). La crisis mundial. Continentalismos, globalismo y pluriversalismo. Bs. As.: Fabro.

Dodds, K. (2012). The Falkland Islands as a "Strategic Gateway". The RUSI Journal, 157(6), 18-25. DOI: https://1 $0.1080 / 03071847.2012 .750882$

Dupuy, H. (octubre 2018). Perspectiva geopolitica del Atlántico Sur en la actual etapa global. I Jornadas Platenses de Geografía, 17 al 19 de octubre de 2018, La Plata, Argentina. Universidad Nacional de La Plata. Facultad de Humanidades y Ciencias de la Educación. Departamento de Geografía. Disponible en: http://www.memoria.f ahce.unlp.edu.ar/trab_eventos/ev.11266/ev.11266.pdf 
Dupuy, H. (octubre 2019). Colonialismo hoy: ¿últimos restos del siglo XX o formas actualizadas de la dependencia? XXI Jornadas de Geografía de la UNLP, 9 al 11 de octubre de 2019, Ensenada, Argentina. Construyendo una Geografía Crítica y Transformadora: En defensa de la Ciencia y la Universidad Pública. Universidad Nacional de La Plata. Facultad de Humanidades y Ciencias de la Educación. Disponible en: http://www.memoria.fahce .unlp.edu.ar/trab_eventos/ev.13537/ev.13537.pdf

Embajada Abierta (25 de enero de 2021). Los llamados Territorios de Ultramar Británicos ante el Brexit. Recuperado de https://www.embajadaabierta.org/post/los-llamados-territorios-de-ultramar-brit\%C3\%A1 nicos-ante-el-br exit

Fornillo, B. (2016). Sudamérica Futuro. China global, transición energética y posdesarrollo. Buenos Aires: El ColectivoCLACSO.

Gandarilla, J., Jalife-Rahme, A., Ceceña, A., Borón, A. y Bruckmann, M. (2016). Geopolítica e integración regional. América Latina en el sistema-mundo. La Paz: Vicepresidencia del Estado Plurinacional de Bolivia.

Global Europe Anticipation Bulletin (GEAB) (28 de septiembre de 2018). Brexit: Una vuelta a la Mancomunidad de Naciones derivada de una asociación comercial más estrecha con la UE. Recuperado de https://geab.eu/es/apercu/brexit-una-vuelta-a-la-mancomunidad-de-naciones-derivada-de-una-asociacioncomercial-mas-estrecha-con-la-ue/

Grosfoguel, R. (2016). Caos sistémico, crisis civilizatoria y proyectos descoloniales: pensar más allá del proceso civilizatorio de la modernidad/colonialidad. Tabula Rasa, 25, 153-174.

Gullo, M. (2015). La insubordinación fundante. Breve historia de la construcción del poder de las naciones. Caracas: El perro y la rana.

Harvey, D. (2014). Diecisiete contradicciones y fin del capitalismo. Quito: IAEN.

Herrera Santana, D. (2016). Hegemonía mundial y recursos geoestratégicos: despliegues espacial/territoriales y fundamentos de la dominación global. En P. Gómez Rey y F. González Luna (Coords.). Acercamientos y reflexiones en torno a la geografía (pp. 145-179). México: UNAM-EÓN.

Jalife-Rahme, A. (25 de octubre de 2015). Gran Bretaña abandona a EU por China: alianza geofinanciera con holandización. La Jornada. Recuperado de https://www.jornada.com.mx/2015/10/25/opinion/012olpol

Jalife-Rahme, A. (6 de julio de 2016). Post-Brexit: Gran Bretaña desecha a Europa por China e India. TeleSUR. Recuperado de https://www.telesurtv.net/bloggers/-Post-Brexit-Gran-Bretana-desecha-a-Europa-por-China-e -India-20160706-0003.html

Lerena, C. (18 de junio de 2020). ¿Quién ejerce el poder en el Atlántico Sur? (5ta. Parte) «La Cuarta Invasión Británica a la Argentina». Sociedad Argentina de Estudios Estratégicosy Globales. Recuperado de https://saeeg.org/index.p hp/2020/06/18/quien-ejerce-el-poder-en-el-atlantico-sur-5ta-parte-la-cuarta-invasion-britanica-la-argentina/

Lerena, C. (1 de enero de 2021). Brexit, Malvinas, pesca y Estados de bandera. Agenda Malvinas. Recuperado de http s://agendamalvinas.com.ar/2021/01/01/brexit-malvinas-pesca-y-estados-de-bandera/

López, J. (2012). Una visión de futuro. La geopolítica de Alfred Mahan. Revista Universidad EAFIT, 29(91), 73-80.

Lualdi, E. (Ed.) (2019). La cuestión Malvinas, una realidad vigente. Actualización / 2019. Bs. As.: Cuadernos para el encuentro de una nueva huella argentina. Edición $\mathrm{N}^{\circ} 57$.

Merino, G. E. (2016). Tensiones mundiales, multipolaridad relativa y bloques de poder en una nueva fase de la crisis del orden mundial. Perspectivas de América Latina. Geopolitica(s): revista de estudios sobre espacio y poder, 2(7), 201-225.

Merino, G. y Narodowski, P. (Coords.) (2019). Geopolitica y economia mundial: El ascenso de China, la era Trump y América Latina. La Plata: EDULP.

Methol Ferré, A. (2009). Los Estados continentales y el Mercosur. Bs. As.: Instituto Jauretche.

Meyssan, T. (4 de julio de 2016). La nueva política exterior británica. Red Voltaire. Recuperado de https://www.vol tairenet.org/article192716.html 
Muñoz Portillo, J. M. (2019). Populismos de derecha en el siglo XXI: El fenómeno, el debate y el caso del presidente Donald Trump en Estados Unidos. Universidad de Costa Rica. Recuperado de http://www.kerwa.ucr.ac.cr/h andle/10669/79915

Ortega, F.; Saavedra, D. y Esquiroz, F. (noviembre 2019). Licencia para depredar: el extractivismo pesquero en Malvinas. Ponencia presentada en II Jornadas sobre la Cuestión Malvinas en la UNLP, La Plata.

Otero Iglesias, M. (2016). Mirando el "Brexit" desde la City: una historia de dinero y poder. Política Exterior, N 76 , 45-51.

Patronelli, H. (noviembre 2017). Re-significar Malvinas para re-pensarlo en clave geopolitica: una mirada desde el Sur global. Jornadas sobre la Cuestión Malvinas: Investigaciones y Debates a 35 Años de la Guerra, 10 de noviembre de 2017, La Plata, Argentina. Disponible en: http://www.memoria.fahce.unlp.edu.ar/trab_eventos/ev.10470/ ev.10470.pdf

Pérez, M. y Barassi, S. (2018). Geopolítica del Atlántico Sur. Desarrollo e integración para defender la soberanía en el siglo XXI. Voces en el Fénix, 8(69), 40-47.

Ramonet, I. (25 de abril de 2020). La pandemia y el sistema-mundo. El Dipló. Recuperado de https://www.eldiplo.o $\mathrm{rg} /$ wp-content/uploads/2020/04/Ramonet-pandemia-sistema-mundo.pdf

Ramos, R. (13 de marzo de 2019). El primer Brexit. La Vanguardia. Recuperado de https://www.lavanguardia.com/ internacional/20190313/461009237447/brexit-reino-unido-precedentes-enrique-viii.html

Recce, J. (2012). Una nueva identidad estratégica nacional: Argentina país austral, suramericano y emergente. Argentina en Asuntos Estratégicos, $\mathrm{N}^{\circ} 1,37-48$.

Sala, J. E. (2018). Pampa Azul. El mar como territorio. Ciencia, tecnología y politica, 1(1), e006. DOI: https://doi.or $\mathrm{g} / 10.24215 / 26183188 \mathrm{e} 006$

Sánchez, A. (5 de junio de 2018). Soberanía en peligro: el macrismo y la cuestión Malvinas. CENACK. Recuperado de https://cenack.com/soberania-en-peligro-el-macrismo-y-la-cuestion-malvinas/

Shaxson, N. (5 de agosto de 2018). The finance curse: how the outsized power of the City of London makes Britain poorer. The Guardian. Recuperado de: https://www.theguardian.com/news/2018/oct/05/the-finance-curse-h ow-the-outsized-power-of-the-city-of-london-makes-britain-poorer

Wainer, L. (Coord.) (2020). Malvinas en la geopolitica de América Latina: de causa regional a recomposición neocolonial. Buenos Aires: Ediciones del CCC Floreal Gorini.

\section{FuenTES}

Esteban, J. (20 de marzo de 2017). El legado del Imperio británico. El Orden Mundial. Recuperado de https://elord enmundial.com/el-legado-del-imperio-britanico/

Falkland Islands Government (2019). State of the Falkland Islands Economy 2018. Policy and Economic Development Unit. Recuperado de https://www.fig.gov.fk/policy/component/jdownloads/send/5-reports-an d-publications/123-state-of-the-falkland-islands-economy-2018?option=com_jdownloads

Foreign and Commonwealth Office (2012). The Overseas Territories. Security, Success and Sustainability. Recuperado de https://assets.publishing.service.gov.uk/government/uploads/system/uploads/attachment_dat a/file/32952/ot-wp-0612.pdf

Her Majesty Government (13 de junio de 2018a). Collection. Global Britain: delivering on our international ambition. Recuperado de https://www.gov.uk/government/collections/global-britain-delivering-on-our-inter national-ambition

Her Majesty Government (2018b). National Security Capability Review. Recuperado dehttps://assets.publishing.service.gov.uk/government/uploads/system/uploads/attachment_data/file/70534 7/6.4391_CO_National-Security-Review_web.pdf

Her Majesty Government (2018c). The government's vision of Global Britain and the role of the Foreign and Commonwealth Office in supporting and enabling government departments to deliver this vision: 
memorandum for the Foreign Affairs Select Committee. Recuperado de https://publications.parliament.uk/p a/cm201719/cmselect/cmfaff/780/78008.htm\#_idTextAnchor035

Mercopress (18 de octubre de 2019). Garantías de Londres a Falklands y sus exportaciones en un "Brexit sin acuerdo". South Atlantic News Agency. Recuperado de https://es.mercopress.com/2019/10/18/garantias-de-londres-a-f alklands-y-sus-exportaciones-en-un-brexit-sin-acuerdo

Ministerio de Relaciones Exteriores y Culto (MREC) (2015). La Comunidad Internacional y la Cuestión Malvinas. República Argentina.

Museo Virtual Malvinas. Observatorio Malvinas. Universidad Nacional de Lanús. Disponible en http://centrougart e.unla.edu.ar/museomalvinas/inicio.php

Penguin News (7 de enero de 2021). Falklands disappointed and frustrated with Brexit deal. Recuperado de https:// penguin-news.com/headlines/politics/2021/falklands-disappointed-and-frustrated-with-brexit-deal/

Red Voltaire (3 de febrero de 2019). La Unión Europea ve ahora Gibraltar como una «colonia» del Reino Unido. En https://www.voltairenet.org/article205009.html

The Commonwealth (2018a). Commonwealth Heads of Government Meeting Communiqué "Towards a Common Future". Recuperado de: http://thecommonwealth.org/sites/default/files/inline/CHOGM_2018_Communi que.pdf

The Commonwealth (2018b). Commonwealth Blue Charter. Recuperado de https://bluecharter.thecommonwealth .org/wp-content/uploads/2019/08/Commonwealth_Blue_Charter.pdf

UK Parliament (19 de junio de 2020). Carta del Parlamentario Alistair Carmichael al Primer Ministro Boris Johnson. En http://s.rfi.fr/media/display/e2d77b78-b7ad-11ea-912c-005056bf87d6/ACarmichael_xpartylett er_ChagosIslands_signed.pdf

Vázquez del Faro (24 de abril de 2019). Foto-reportaje: La militarización de las Islas Malvinas. OCIPEX. En https:// ocipex.com/foto-reportaje-la-militarizacion-de-las-islas-malvinas/

Williamson, G. (11 de febrero de 2019). Defence in Global Britain. Speech. Disponible en https://www.gov.uk/gov ernment/speeches/defence-in-global-britain

\section{Notas}

1 Se debe mencionar también el mega proyecto de canal interoceánico en Nicaragua, que podría representar una alternativa al de Panamá, país que se ha alineado históricamente con EEUU. Tal proyecto fue anunciado en 2012 y sería construido por empresarios chinos, aunque su ejecución se estancó y nunca se llevó a cabo. A la par, en 2017 China estableció relaciones diplomáticas con Panamá, buscando constituir el canal de ese país como puerta de entrada para la "Nueva Ruta de la Seda".

2 El Almirante Segundo Storni, activo promotor de los intereses argentinos en el mar a inicios de siglo XX, fue de los primeros en alertar que las Malvinas, en otras manos, son como una pistola gigantesca apuntando al corazón del país, como señala Javier De Guernica (citado en Cisilino, 2020). Ello no puede ser desvinculado, a su vez, de los intereses británicos en el continente, sobre lo cual se pueden señalar dos ejemplos paradigmáticos: por un lado, la compra de tierras patagónicas por parte de ciudadanos británicos en las últimas décadas, siendo el caso de "Joe" Lewis el más conocido, con un aeropuerto y la previsión de construir otro, estimándose que sus tierras ocuparían casi todo el ancho del territorio continental patagónico argentino, encontrándose a 2 hs. de avión de Malvinas. Por otro lado, el principal yacimiento hidrocarburífero (convencional) argentino, Cerro Dragón, ubicado en la Cuenca del Golfo San Jorge, es operado por Pan American Energy (PAE), una de las principales compañías del sector en el país y que está integrada por la petrolera de origen local Bridas (la cual pertenece en partes iguales, desde 2010, a la familia Bulgheroni y a la china CNOOC) y la británica BP (anteriormente denominada British Petroleum).

3 “(1) Zona Económica Exclusiva Argentina (ZEEA), parte de ella por el Tratado del Río de la Plata y su frente Marítimo, Zona Común de Pesca con Uruguay, con bajo control de las fuerzas armadas y de seguridad argentinos que, junto con los espacios invadidos por el Reino Unido de Gran Bretaña alcanzan a los 3.146.345 de $\mathrm{km}^{2}$. Zona periódicamente invadida por buques extranjeros ilegales; (2) ZEEA ocupada por la fuerza por el Reino Unido, de unos $438.000 \mathrm{Km}^{2}$, denominada por los británicos FICZ (Falklands Interim Conservation and Management); (3) Zona llamada del "gallinero" o "medialuna" acordada con fines de conservación por el RU y la Cancillería Argentina 
(Cavallo), denominada por los británicos FOCZ (Falklands Outer Conservation Zona), de unos $400 \mathrm{mil} \mathrm{km}^{2}$; (4) Espacio establecido y denominada GAP en forma unilateral por los británicos dentro de la ZEEA, rica en calamar de unos $1.900 \mathrm{Km}^{2}$; (5) Área Marítima Protegida determinada en forma ilegal por el Reino Unido en territorio marítimo argentino, de $1.070 .000 \mathrm{Km}^{2}$ alrededor de las Islas Georgias del Sur y Sandwich del Sur; (6) Área pretendida por el RU sobre la Plataforma Continental Argentina y la Antártida Argentina, que se superpone con los derechos argentinos de esos espacios; (7) Área Marítima Protegida (AMP) "Namuncurá” establecida por Argentina de unos $32.336 \mathrm{Km}^{2}$ que facilita el desarrollo de las especies que migran hacia el área de Malvinas; (8) Área de $100.000 \mathrm{Km}^{2}$ de explotación offshore petrolera otorgada a varias empresas inglesas o con vínculos con Malvinas (9) Área de 150 millas más allá de la ZEE Argentina, un espacio marítimo estimado en unos $600.000 \mathrm{Km}^{2}$ pretendido por el Acuerdo de conservación y explotación entre OPRAS [Organización para la Protección de los Recursos Pesqueros del Atlántico Sur] y las Cámaras españolas y argentinas (CAPECA-CAPA). Todo ello agravado porque el Acuerdo de Investigación Conjunta de Pesca entre Argentina y el RU, a través de la Comisión de Pesca del Atlántico Sur (CPAS), se extiende en un área marítima que excede la zona de exclusión ilegal británica en Malvinas (hoy suspendido)” (Lerena, 2020).

4 El apoyo de los 32 miembros de la Cumbre de Países de América Latina y el Caribe a la posición argentina, en 2010, resultó una gran preocupación para el Reino Unido, debido a que por primera vez se sumaban a ello los países caribeños integrantes del Commonwealth.

5 Mientras que el Brexit implicó un fuerte golpe sobre la UE, alentando un cuestionamiento a su pervivencia como bloque continental de poder, también puso en juego la preminencia de la city londinense como principal centro financiero europeo (debido al peligro de perder el denominado "pasaporte financiero"). Ello dio lugar a una disputa del poder financiero global para suceder ese lugar, principalmente entre Frankfurt, París y Ámsterdam. Sobre la disputa de modelos de acumulación y desarrollo en Reino Unido, se puede consultar el cuerpo de investigaciones económicas sobre la "maldición financiera", que afirma que la sobredimensionada y desmedida magnitud de la city de Londres ha empobrecido la economía real británica (Shaxson, 2018).

6 Se puede rastrear la génesis de este conflicto al menos hasta el siglo XIX, luego de la batalla de Waterloo, en 1815, en que el Imperio británico se impuso a Napoleón. Ante su nuevo lugar de potencia hegemónica, la city de Londres desplazó a Ámsterdam como principal centro financiero y se gestaron en ella dos "almas": uno nativista, de carácter conservador, patriótico e insular, de menor poder relativo en la actualidad, y otro de carácter cosmopolita y globalista, que ha sido el sector dominante (Otero Iglesias, 2016). En la actualidad, este conflicto entre globalistas y nacionalistas recorre todo el polo de poder angloamericano, es decir, tanto EEUU como RU, siendo predominantemente multilateralistas y neoliberales los primeros, y unilateralistas y neoconservadores los segundos (Merino, 2016).

7 Reino Unido es la potencia con mayor cantidad de colonias en la actualidad, sosteniendo 10 de los 17 territorios "no autónomos” que reconoce la Organización de las Naciones Unidas a través de su Comité de Descolonización (esos 10 están incluidos en los BOT). No obstante, más allá de ello, Dupuy (2019) identifica un total aproximado de 70 territorios coloniales, con diversas particularidades institucionales y relaciones con sus respectivas metrópolis (algunos de ellos contabilizados separadamente y otros agrupados por estructuras institucionales metropolitanas).

8 Este es el término clave para los británicos: los deseos de sus habitantes, según lo cual pueden manipular el principio de autodeterminación de los pueblos. Argentina no reconoce este punto (al menos bajo sus gobiernos que han defendido el reclamo de soberanía sobre Malvinas), y expresa la necesidad de reconocer los intereses de los isleños en cualquier solución al conflicto, pero no sus deseos, al tratarse de una población trasplantada luego de una "limpieza étnica" británica sobre las islas luego de su usurpación en 1833.

9 La "desmalvinización” constituye un dispositivo discursivo e ideológico que se afianzó en la cultura y el sentido común argentinos de posguerra a través del accionar británico y de las clases dominantes argentinas, con el fin de minar el sentimiento patriótico, heroico y antiimperialista en torno a Malvinas en la cultura popular. Ver para profundizar en ello: Cangiano, 2019.

10 No se debe perder de vista, no obstante, las iniciativas enmarcadas en el horizonte de diplomacia cultural o poder blando llevadas a cabo por el embajador británico Mark Kent frente a los más altos estamentos ministeriales del Estado argentino, en consonancia con la estrategia de Global Britain. 